\title{
Sex Differences in the Brain's Dopamine Signature of Cigarette Smoking
}

\author{
Kelly P. Cosgrove, ${ }^{1,2,3 *}$ - Shuo Wang, ${ }^{1,4 *}$ Su-Jin Kim, ${ }^{1,2}$ Erin McGovern, ${ }^{3}$ @Nabeel Nabulsi, ${ }^{1,2}$ Hong Gao, ${ }^{1,2}$ \\ David Labaree, ${ }^{1,2}$ Hemant D. Tagare, ${ }^{2,4}$ Jenna M. Sullivan, ${ }^{1,4}$ and Evan D. Morris ${ }^{1,2,3,4}$ \\ ${ }^{1}$ Yale PET Center, ${ }^{2}$ Department of Diagnostic Radiology, ${ }^{3}$ Department of Psychiatry, and ${ }^{4}$ Department of Biomedical Engineering, Yale University, New \\ Haven, Connecticut 06519
}

Cigarette smoking is a major public health danger. Women and men smoke for different reasons and cessation treatments, such as the nicotine patch, are preferentially beneficial to men. The biological substrates of these sex differences are unknown. Earlier PET studies reported conflicting findings but were each hampered by experimental and/or analytical limitations. Our new image analysis technique, lp-ntPET (Normandin et al., 2012; Morris et al., 2013; Kim et al., 2014), has been optimized for capturing brief (lasting only minutes) and highly localized dopaminergic events in dynamic PET data. We coupled our analysis technique with high-resolution brain scanning and high-frequency motion correction to create the optimal experiment for capturing and characterizing the effects of smoking on the mesolimbic dopamine system in humans. Our main finding is that male smokers smoking in the PET scanner activate dopamine in the right ventral striatum during smoking but female smokers do not. This finding-men activating more ventrally than women-is consistent with the established notion that men smoke for the reinforcing drug effect of cigarettes whereas women smoke for other reasons, such as mood regulation and cue reactivity. Ip-ntPET analysis produces a novel multidimensional endpoint: voxel-level temporal patterns of neurotransmitter release ("DA movies") in individual subjects. By examining these endpoints quantitatively, we demonstrate that the timing of dopaminergic responses to cigarette smoking differs between men and women. Men respond consistently and rapidly in the ventral striatum whereas women respond faster in a discrete subregion of the dorsal putamen.

Key words: dopamine; PET; raclopride; reinforcement; sex differences; tobacco smoking

\section{Introduction}

Tobacco smoking remains the leading cause of preventable death worldwide. Most smokers want to quit smoking, but few are able. Women have more difficulty quitting than men (Perkins et al., 2001; Piper et al., 2010). They report more negative affect (Xu et al., 2008; Langdon et al., 2013; Doran, 2014) and greater cueinduced craving (Field and Duka, 2004; Carpenter et al., 2014; Doran, 2014) than men during acute withdrawal. Men tend to be more reinforced by the nicotine in cigarettes, that is, they are more sensitive to the nicotine level (Perkins et al., 2001). Unfortunately, the neurobiological bases for these sex differences are unknown so it has been difficult to design gender-sensitive treatments. The nicotine in cigarettes activates nicotinic AChRs located on DA neurons leading to the release of DA in

Received Sept. 2, 2014; revised 0ct. 6, 2014; accepted Nov. 3, 2014.

Author contributions: K.P.C., S.-J.K., H.D.T., J.M.S., and E.D.M. designed research; K.P.C., S.W., E.M., N.N., H.G., D.L., J.M.S., and E.D.M. performed research; K.P.C., S.W., S.-J.K., H.D.T., J.M.S., and E.D.M. analyzed data; K.P.C., S.W., and E.D.M. wrote the paper.

This work is supported by National Institute on Drug Abuse (R21DA032791 and K02DA031750) and the Office of Research on Women's Health (P50DA033945). We thank the Yale PET Center staff for imaging and chemistry support.

*K.P.C. and S.W. contributed equally to this work.

The authors declare no competing financial interests.

Correspondence should be addressed to Evan D. Morris, Yale PET Center, 801 Howard Avenue, New Haven, CT 06519. E-mail: evan.morris@yale.edu.

DOI:10.1523/JNEUROSCI.3661-14.2014

Copyright $\odot 2014$ the authors $\quad 0270-6474 / 14 / 3416851-05 \$ 15.00 / 0$ the mesolimbic DA system (Imperato et al., 1986). Dopamine is implicated in the reinforcing effects of nicotine, mood regulation, and the saliency of cues and may, therefore, have a primary role in regulating sex differences in response to smoking.

Previous studies have used PET to measure smoking-induced striatal DA release (Barrett et al., 2004; Brody et al., 2004, 2006; Scott et al., 2007); none were designed to examine effects of sex. These earlier studies relied on methods that were "tuned" to detect sustained alterations of DA release (Sullivan et al., 2013), but, in fact, the DA-ergic response to cigarette smoking is brief (on the order of minutes). We have optimized a new method ("lp-ntPET") for identifying highly localized DA transients in PET data (Morris et al., 2005, 2013; Normandin et al., 2012; Kim et al., 2014), which allows us to probe the short-lived striatal DA responses to cigarette smoking on a voxel-by-voxel basis. In doing so, we create dynamic images ("DA movies"; Morris et al., 2013) of the brain from $\left[{ }^{11} \mathrm{C}\right]$ raclopride PET scans. DA movies are a new way of visualizing rapidly changing DA levels during smoking. With this method of analysis, the patterns of DA change with time need not be the same in different voxels. The strength of lp-ntPET over conventional methods is twofold. One, it is tuned to detect short-lived events, and is thus ideal for imaging the DA response to cigarette smoking. Two, the resulting DA movies contain previously unmeasurable timing information about DA activation in subregions of the striatum, in vivo. With lp-ntPET 
we can ask both "where" and "how much faster" the DA event was in one group versus another.

As a group, male smokers are known to be more sensitive than women smokers to the drug (nicotine) effects of cigarette smoking (Perkins et al., 2001). It has also been shown in animal studies that ventral striatal activation is involved in the initial stages of addiction but that at later stages, drug taking activates areas of dorsal striatum that are commonly associated with habit (Porrino et al., 2004; Everitt and Robbins, 2013). To explain these known sex differences in smokers, we hypothesized that smoking must elicit some form of ventral striatal dopamine activation in men that, if it exists at all, is less pronounced in women.

\section{Materials and Methods}

Subjects. Sixteen nicotine-dependent tobacco smokers (eight males: $42.9 \pm 7.4$ years, eight females: $33.1 \pm 9.7$ years; $p=0.04$ ) were studied. Males and females were matched for dependence level using the Fagerström Test for Nicotine Dependence (FTND; Heatherton et al., 1991; male FTND score $=5.5 \pm 0.7$; female FTND score $=4.9 \pm 0.6 ; p=0.5$ ) and years smoked (males $19.9 \pm 2.1$ years; females $17.0 \pm 3.3$ years; $p=$ 0.2 ). Participants had no history of significant medical illness or major head trauma. All Axis I disorders except for nicotine dependence were ruled out. Smoking status was confirmed by plasma cotinine levels $>150$ $\mathrm{ng} / \mathrm{ml}$, urine cotinine levels $>100 \mathrm{ng} / \mathrm{ml}$ (NicAlert cotinine test strips; Nymox Pharmaceutical), and CO levels $>11 \mathrm{ppm}$ on the day of intake. Subjects were instructed to abstain from any form of nicotine replacement therapy or medication during their participation. Overnight abstinence was confirmed with breath CO levels $<10 \mathrm{ppm}$. Plasma nicotine and cotinine levels were measured as previously described (Staley et al., 2006). The study was approved by the Yale Human Investigation and Radiation Safety Committees.

Scanning. A $3 \mathrm{~T}$ structural MRI scan for anatomical localization was collected from each subject. $\left[{ }^{11} \mathrm{C}\right]$ raclopride, a D2 antagonist, was prepared as previously described (Morris et al., 2005; Normandin et al., 2012). Before each PET, a 6 min transmission scan was acquired for attenuation correction. $\left[{ }^{11} \mathrm{C}\right]$ raclopride was administered as an initial bolus followed by a constant infusion for $90 \mathrm{~min}\left(K_{\mathrm{bol}}=105 \mathrm{~min}\right)$. The mean radioactivity dose was $17.0 \pm 2.2 \mathrm{mCi}$ (men: $18.0 \pm 1.4 \mathrm{mCi}$; women: $16.1 \pm 2.5 \mathrm{mCi} ; p=0.1$ ). PET was performed with the HighResolution Research Tomograph (Siemens/CTI; FWHM $=2-3 \mathrm{~mm}$ ). During the scan, subjects smoked either one or two cigarettes of their own brand, at their own pace, starting at mid-session (35 min or $45 \mathrm{~min}$ after scan start) without leaving the scanner. (The protocol was changed from 45 to 35 min for start of smoking after the first two men and two women were scanned, and from two to one cigarette after the first five men and five women. Results were consistent across protocols.) As part of a test/retest study, four of the males underwent a second scan with identical conditions no earlier than 1 week later. To eliminate secondhand smoke, an air filter (Movex) was positioned in front of the scanner and above the subject's head for the scan duration.

Image reconstruction. PET data were acquired in list mode and reconstructed with MOLAR (Carson et al., 2004) correcting for motion on the event level using the high-frequency motion detection system (Polaris Vicra Tracking System; Northern Digital). MOLAR also corrects for scatter, attenuation, dead-time, normalization, scanner geometry, and point-spread function. Emission images were binned into 3 min frames. Images were de-noised with HYPR (Christian et al., 2010) to reduce spatial noise but to preserve critical temporal information. PET data were aligned to the subject's MRI and then to a standard MRI template with isotropic voxels ( $2 \mathrm{~mm}$ edges). A mask of the precommissural striatum (ventral striatum, dorsal caudate, and dorsal putamen) was applied to all PET data in template space (Martinez et al., 2003). Investigation of DA activation was limited to the mask area.

DA movies and parametric images. DA movies were created from dynamic PET datasets according to our published methods (Normandin et al., 2012; Morris et al., 2013; Kim et al., 2014). lp-ntPET is a model of tracer uptake, containing a time-varying term for effects of changes in neurotransmitter concentration. Unlike LSSRM (Alpert et al., 2003), which also incorporated a time-varying term, lp-ntPET does not constrain DA curves to be one shape. The operational equation of lp-ntPET is linear in parameters so it can be fitted reliably and rapidly at every voxel:

$$
\begin{aligned}
C_{T}(t)=R_{1} C_{R}(t)+k_{2} \int_{0}^{t} C_{R}(u) d u-k_{2 a} \int_{0}^{t} C_{T}(u) d u & \\
& -\gamma \int_{0}^{t} C_{T}(u) h(t) d u
\end{aligned}
$$

$C_{T}$ and $C_{R}$ are the concentrations in the target and reference region, respectively. $R_{1}$ is the delivery ratio, $k_{2}$ is the transfer rate constant between the free compartment and plasma, and $k_{2 a}$ is the apparent efflux rate constant between the target tissue (taken as one compartment) and the plasma. $h(t)$ represents the time course of activation (i.e., DA elevation above baseline) and $\gamma$ encodes the magnitude of effect on $k_{2 a}$. Each of the response profiles, $h_{i}(t)$, are parameterized as gamma variates and exponentials. The best response to explain the PET time-activity curve (TAC) at a voxel is selected from a precomputed library of 300 response functions. We used the gamma-variate formulation of Madsen (1992):

$$
h_{i}(t)=\left(\frac{t-t_{D}}{t_{P}-t_{D}}\right)^{\alpha} \exp \left(\alpha\left[1-\frac{t-t_{D}}{t_{P}-t_{D}}\right]\right) u\left(t-t_{D}\right)
$$

where $t_{D}$ is the response start time relative to start of scan, $t_{P}$ is the time of maximal response relative to scan start, and $\alpha$ is the "sharpness."

lp-ntPET was fit to the PET TACs at each voxel in the mask. The display of all response functions simultaneously constitutes a DA movie. In a DA movie, the DA response is retained only for voxels where the inclusion of the time-varying term improves the fit. Improvement is determined by the $F$ test (Kim et al., 2014). lp-ntPET produces novel endpoints. Binary maps of the voxels containing DA responses are referred to as "Significance Masks." Because the DA responses at each voxel are parameterized (Eq. 2) they can be represented as parametric images. Images of the "Peak Height" of DA curves $\left[\gamma^{\star}\right.$ peak $\left.(h(t))\right]$ are produced from the fit of Equation 1. Temporal parameters, "Latency" $\left(t_{D}\right.$, time of cigarette), "Rise Time" $\left(t_{P}-t_{D}\right)$, and "Recovery Time" $\left(\frac{\left(t_{P}-t_{D}\right) \ln 2}{\alpha}\right)$ are derived from $h(t)$.

After the $F$ test, we applied a cluster-size threshold to correct for multiple comparisons. We have estimated that the likelihood of any false positive clusters larger than the predetermined threshold is $10 \%$ or less, overall (Kim et al., 2014).

"Probability of Activation" maps were generated by summing the Significance Masks by group and dividing by number of group members (Fig. 1a). For test/retest subjects the average of their two Significance Masks was used. Spatial extent of activation induced by smoking was quantified as number of voxels activated by smoking and counted by subject in six subregions (left and right ventral striatum, dorsal putamen, and dorsal caudate) of the precommissural striatum (1004 voxels). The statistical significance of the sex difference in the mean number of voxels activated by smoking in a subregion of the mask was assessed with a permutation test. Here, we used significance masks before the application of a cluster-size threshold to assure a continuous distribution in the number of activated voxels. The null hypothesis of the permutation test was that men and women have the same number of smoking-activated voxels. One hundred thousand random resamplings of the 16 subjects were performed to produce pairs of groups of 8 . A distribution of the mean difference in activated voxels by region was generated to assess the likelihood of any given difference occurring by chance.

Two-sample $t$ tests were performed voxel by voxel in SPM8 (http://www.fil.ion.ucl.ac.uk/spm/) on parametric images to locate clusters of voxels that contained significantly different DA timing and/or magnitude between males and females ( $p<0.05$; uncorrected). For comparison of the magnitude of peak DA activation $(\gamma)$, the search volume was limited to the ventral striatum (274 voxels) because our hypoth- 


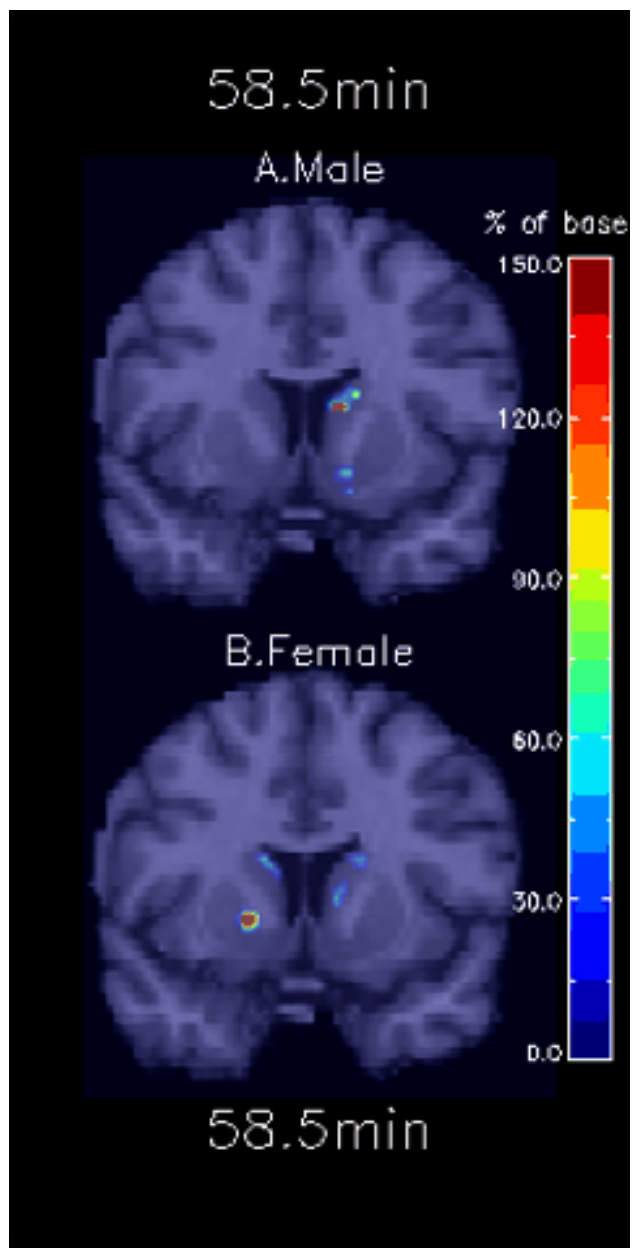

Movie 1. Top row, DA movie of representative male smoker. Bottom, Representative female smoker. Both smokers started smoking at the 45 min point of scan session. Both rows show same coronal slice in AAL template space. The movie is comprised of 3 min frames from 20 min before smoking to end of scan. Color bar, Fractional increase in DA above baseline. Note activation in right ventral striatum in the male smoker. There is no such cluster of activation in the female smoker. The ventral activation in the male appears at $49 \mathrm{~min}$. There are clusters bilaterally in dorsal caudate and one in left dorsal putamen in the female smoker. Right side of brain is on the right.

esis based on the Probability of Activation maps was that men and women would differ there. For comparison of Rise Time, the search volume was limited to the dorsal putamen (408 voxels) because we hypothesized that women activated faster than men in a dorsal area. (Note: size of the search volume had no bearing on significance of our SPM results because we present the peak values uncorrected.) The data for these comparisons were parametric images by group before cluster-size and $F$ test thresholds to guarantee a value in every voxel in the mask of each parametric map.

\section{Results}

Our main finding is that there is significantly more DA activation in the ventral striatum of male versus female smokers. A DA movie showing representative male and female smokers is given in Movie 1. Ventral striatal activation is absent in the female smoker. DA movies of the male smokers are consistent in appearance and distinct from women.

Probability maps for male and female smokers are shown in Figure $1 a$. The maps quantify what is visualized in the movies. A distinct difference between the maps is evident in the number of activated voxels in the right ventral striatum. Men activated significantly more voxels in right ventral striatum than women (18 \pm 6 vs
$4 \pm 1$, respectively; mean $\pm \mathrm{SE}$ ) in response to smoking (Fig. 1b) The results of the permutation test demonstrate that the right ventral striatal difference between maps is highly significant $(p=0.01$; this is a single comparison and does not require correction).

The test/retest comparisons revealed low within-subject variance. The mean difference in number of activated voxels in right ventral striatum was 11 for the four men who underwent two separate smoking scans. This relatively small within-subject variability in spatial extent of activation suggests the possibility of future, withinsubject cross-over studies of treatments.

Figure 2 illustrates both spatial and temporal comparisons between the mean male and female responses to smoking. By comparing DA Peak Height images, we identified a cluster of voxels in which DA peaks were significantly higher in men (Fig. $2 a ; p=0.002$ peak level, uncorrected). The mean DA curves for the identified cluster are shown in Figure $2 b$. The narrow envelopes for each curve (corresponding to mean $\pm \mathrm{SE}$ ) indicate that the men responded rapidly and consistently in the right ventral striatum. In contrast, the women responded mildly, if at all, and without any temporal consistency.

We also identified dorsal striatal voxel values in the DA Rise Time images that were significantly smaller (faster) in women. The largest significant cluster of voxels was in the right dorsal putamen ( $p=0.003$ peak level, uncorrected; Fig. $3 a$ ). Figure $3 b$ shows a labeled canonical DA curve. Figure $3 c$ shows actual mean DA curves for each cohort derived from the voxels in the cluster in Figure $3 a$. The fast Rise Time is evident in the average DA curves (Fig. 3c) for women (pink) as compared with men (blue). Dashed curves are mean \pm SE for the respective curves. In this region it is the male smokers who appear to respond very slowly and moderately, if at all. (Note: because Latency is not constrained to be constant across voxels or subjects, the average curves blur the high frequencies so a fast Rise Time is not maximally evident.)

\section{Discussion}

Our present findings point to DA action in the right ventral striatum as a primary biological substrate underlying sex differences in the drug reinforcement aspect of cigarette smoking. The ventral striatum is the locus of reinforcement and it follows that men, who smoke for the reinforcing effects of nicotine, have significant activations in the ventral striatum, which are characterized by a rapid DA response.

Women are not less dependent on nicotine than men but they tend to smoke for different reasons, including stress and affect regulation that may be more linked to the "habit" of smoking. There must be a unique neurocircuitry that explains the behavior of women smokers and is different from men. We propose that the locus of smoking reinforcement for women may be found in the dorsal striatum, which is also critical for habit formation (Porrino et al., 2004; Yin et al., 2006). Our exploratory analysis of Rise Time images identifies a candidate element of the female neurocircuitry of tobacco smoking addiction. The observed locus with faster DA response in the dorsal putamen of women compared with men may underlie the more prominent habitual aspect of smoking for women smokers. The current study is limited by small sample size; with more subjects we could look everywhere in striatum for timing differences. We did not control for smoking pace or other topography, although it might differ by sex (Weinberger and McKee, 2012).

None of the temporal differences observed could have been discovered without lp-ntPET (Normandin et al., 2012). The con- 


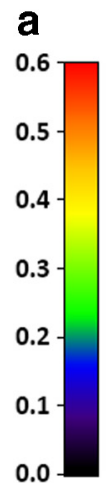

0.0
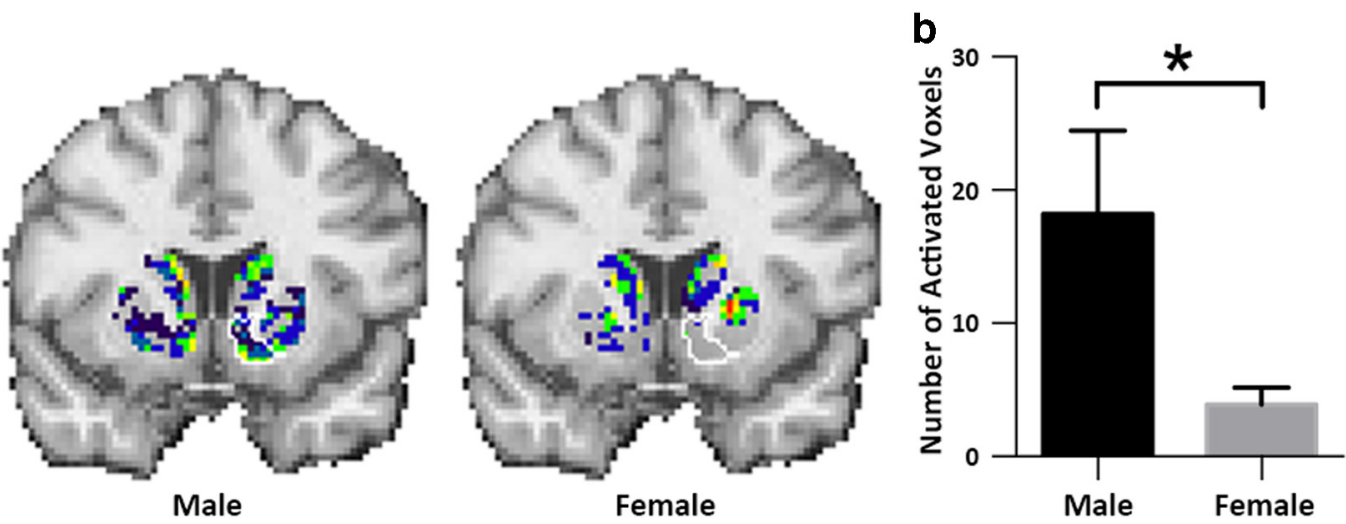

Figure 1. $\boldsymbol{a}$, Probability of activation maps for male and female smokers. Note the striking difference in the right ventral striatum. $\boldsymbol{b}$, The mean (and SE) number of voxels activated during smoking in the right ventral striatum for male and female smokers. A permutation test indicated that the mean sex difference in number of activated voxels in the right ventral striatum was highly significant $(p=0.01)$.

a

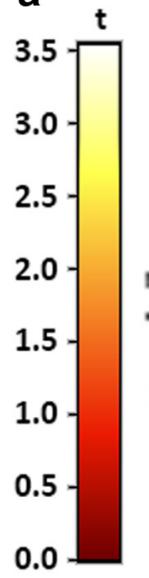

b

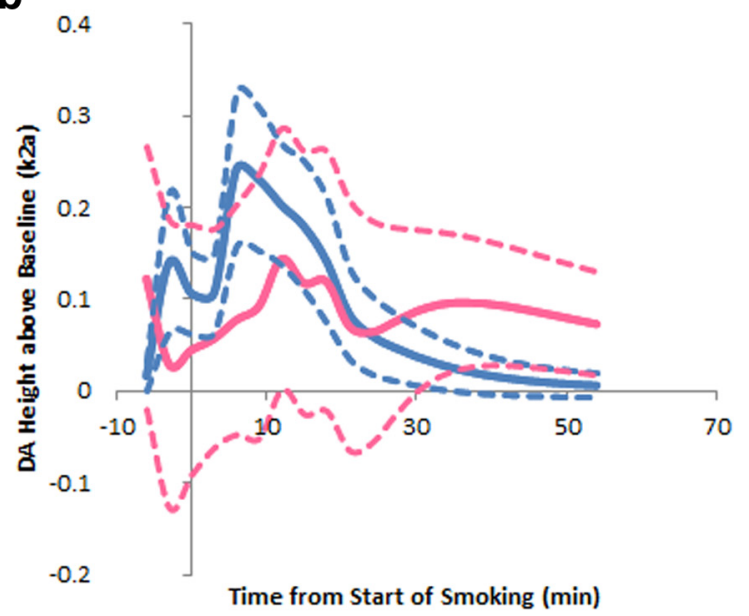

Figure 2. $\quad \boldsymbol{a}$, A cluster of 20 voxels in the right ventral striatum identified by SPM: peak DA level in response to smoking is significantly higher in men than women. $\boldsymbol{b}$, DA curves for the same cluster. The solid curves are the mean DA time courses for men (blue solid curve) and women (pink solid curve). Dashed curves are mean curve $\pm 1 \mathrm{SE}$.
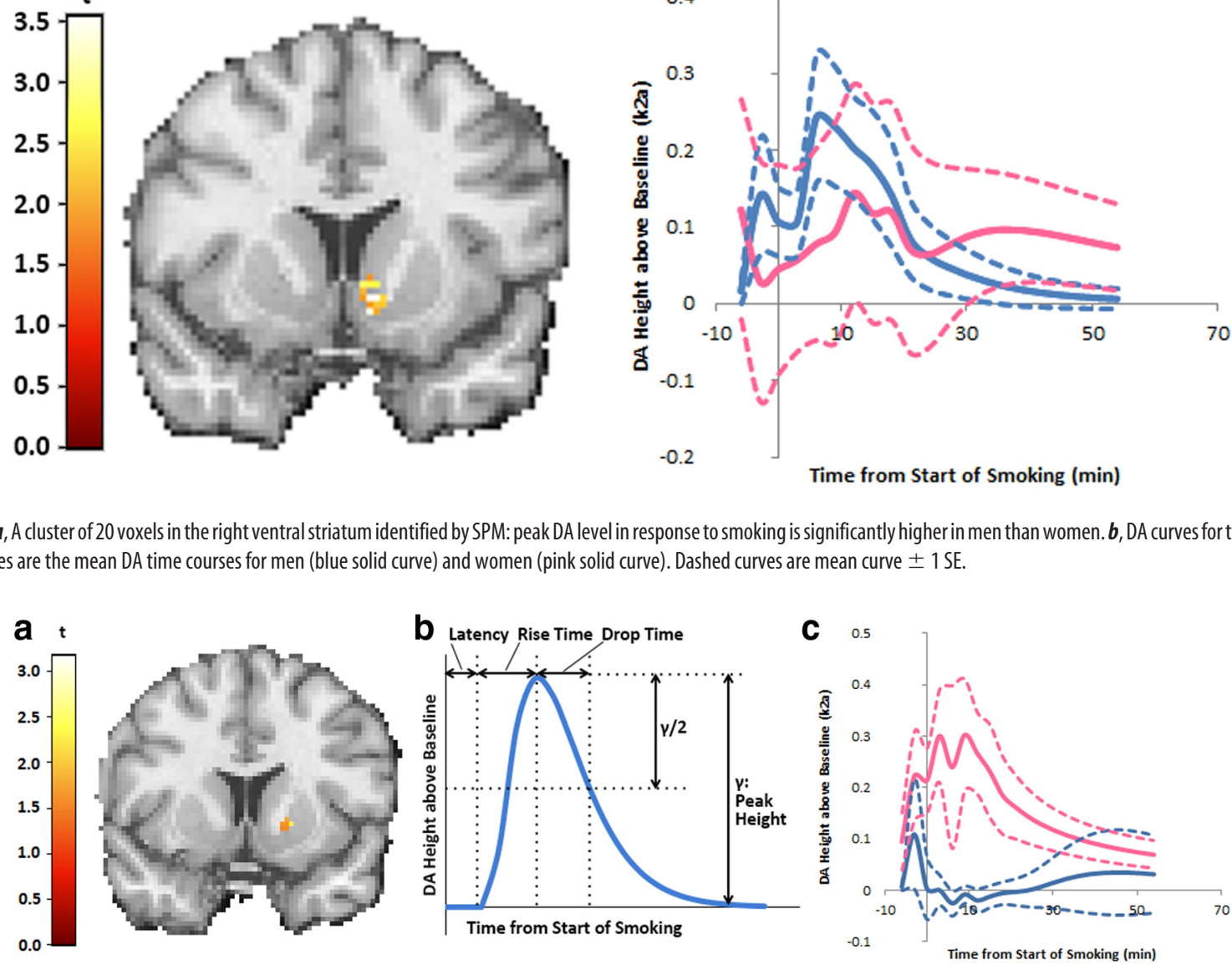

Figure 3. $\quad \boldsymbol{a}$, A nine voxel cluster in the right dorsal putamen identified by SPM: women responded significantly faster to smoking (shorter Rise Time) versus men. $\boldsymbol{b}$, Illustration of the DA parameters that characterize a DA time course. $c$, The solid curves are the mean DA time courses for men (blue solid curve) and women (pink solid curve). Dashed curves are mean curve \pm 1 SE.

ventional models of dynamic PET data typically estimate binding potential as an endpoint. But binding potential-a single static parameter-cannot convey both magnitude (of DA change) and timing (Yoder et al., 2004). Even LSSRM (Alpert et al., 2003), which contains a term for time variation in DA, does not allow for different timing parameters in different voxels or cohorts as does lp-ntPET. Had we used LSSRM, we could not have uncovered spatiotemporal differences in male and female responses to smoking. Our test/retest results, although limited, give confi- dence to the differences in probability of activation maps (Fig. 1) and suggest that our novel endpoints could be used for withinsubject studies. We have shown previously, with simulations relevant to cigarette smoking, that given 100 subjects, only 10/100 DA movies would have any false positive clusters. Watching the movies over and over, we were struck by the differences between men and women. Our desire to quantify what we saw lead us to explore the spatial extent of activation (Christian et al., 2006; Yoder et al., 2007) and to the probability of activation maps. The 
response to smoking is short lived, and thus well suited to lpntPET analysis, but we foresee the method having application for detecting brief neurochemical responses to (nonpharmacological) tasks performed in the PET scanner.

In earlier work with a nicotinic ligand, we discovered sex differences in the long-term regulatory effects of smoking on nicotinic receptors (Cosgrove et al., 2012). Others have shown differential long-term effects of smoking on DA receptors in men versus women (Brown et al., 2012). Thanks to our novel analysis tool (Kim et al., 2014), the current study is the first to demonstrate spatial and temporal differences in the cigarette smoking-induced "DA signature" of nicotine-dependent men and women. The DA signature of smoking may represent an important multidimensional biomarker of smoking dependence and a tool for the development of gender-sensitive medications for smoking cessation.

\section{References}

Alpert NM, Badgaiyan RD, Livni E, Fischman AJ (2003) A novel method for noninvasive detection of neuromodulatory changes in specific neurotransmitter systems. Neuroimage 19:1049-1060. CrossRef Medline

Barrett SP, Boileau I, Okker J, Pihl RO, Dagher A (2004) The hedonic response to cigarette smoking is proportional to dopamine release in the human striatum as measured by positron emission tomography and [11C] raclopride. Synapse 54:65-71. CrossRef Medline

Brody AL, Olmstead RE, London ED, Farahi J, Meyer JH, Grossman P, Lee GS, Huang J, Hahn EL, Mandelkern MA (2004) Smoking-induced ventral striatum dopamine release. Am J Psychiatry 161:1211-1218. CrossRef Medline

Brody AL, Mandelkern MA, Olmstead RE, Scheibal D, Hahn E, Shiraga S, Zamora-Paja E, Farahi J, Saxena S, London ED, McCracken JT (2006) Gene variants of brain dopamine pathways and smoking-induced dopamine release in the ventral caudate/nucleus accumbens. Arch Gen Psychiatry 63:808-816. CrossRef Medline

Brown AK, Mandelkern MA, Farahi J, Robertson C, Ghahremani DG, Sumerel B, Moallem N, London ED (2012) Sex differences in striatal dopamine D2/D3 receptor availability in smokers and non-smokers. Int J Neuropsychopharmacol 15:989-994. CrossRef Medline

Carpenter MJ, Saladin ME, Larowe SD, McClure EA, Simonian S, Upadhyaya HP, Gray KM (2014) Craving, cue reactivity, and stimulus control among early-stage young smokers: effects of smoking intensity and gender. Nicotine Tob Res 16:208-215. CrossRef Medline

Carson RE, Barker WC, Liow JS, Johnson CA (2004) Design of a motioncompensation OSEM list-mode algorithm for resolution-recovery reconstruction for the HRRT. IEEE Nuclear Science Symposium, Portland, OR, pp 3281-3285.

Christian BT, Lehrer DS, Shi B, Narayanan TK, Strohmeyer PS, Buchsbaum MS, Mantil JC (2006) Measuring dopamine neuromodulation in the thalamus: using [F-18]fallypride PET to study dopamine release during a spatial attention task. Neuroimage 31:139-152. CrossRef Medline

Christian BT, Vandehey NT, Floberg JM, Mistretta CA (2010) Dynamic PET denoising with HYPR processing. J Nucl Med 51:1147-1154. CrossRef Medline

Cosgrove KP, Esterlis I, McKee SA, Bois F, Seibyl JP, Mazure CM, Krishnan-Sarin S, Staley JK, Picciotto MR, O'Malley SS (2012) Sex differences in availability of beta $2^{\star}$-nicotinic acetylcholine receptors in recently abstinent tobacco smokers. Arch Gen Psychiatry 69:418-427. CrossRef Medline

Doran N (2014) Sex differences in smoking cue reactivity: craving, negative affect, and preference for immediate smoking. Am J Addict 23:211-217. CrossRef Medline

Everitt BJ, Robbins TW (2013) From the ventral to the dorsal striatum: devolving views of their roles in drug addiction. Neurosci Biobehav Rev 37:1946-1954. CrossRef Medline

Field M, Duka T (2004) Cue reactivity in smokers: the effects of perceived cigarette availability and gender. Pharmacol Biochem Behav 78:647-652. CrossRef Medline

Heatherton TF, Kozlowski LT, Frecker RC, Fagerström KO (1991) The Fagerstrom test for nicotine dependence: a revision of the Fagerstrom tolerance questionnaire. Br J Addict 86:1119-1127. CrossRef Medline

Imperato A, Mulas A, Di Chiara G (1986) Nicotine preferentially stimulates dopamine release in the limbic system of freely moving rats. Eur J Pharmacol 132:337-338. CrossRef Medline

Kim SJ, Sullivan JM, Wang S, Cosgrove KP, Morris ED (2014) Voxelwise lp-ntPET for detecting localized, transient dopamine release of unknown timing: sensitivity analysis and application to cigarette smoking in the PET scanner. Hum Brain Mapp 35:4876-4891. CrossRef Medline

Langdon KJ, Leventhal AM, Stewart S, Rosenfield D, Steeves D, Zvolensky M] (2013) Anhedonia and anxiety sensitivity: prospective relationships to nicotine withdrawal symptoms during smoking cessation. J Stud Alcohol Drugs 74:469-478. Medline

Madsen MT (1992) A simplified formulation of the gamma variate function. Phys Med Biol 37:1597-1600. CrossRef

Martinez D, Slifstein M, Broft A, Mawlawi O, Hwang DR, Huang Y, Cooper T, Kegeles L, Zarahn E, Abi-Dargham A, Haber SN, Laruelle M (2003) Imaging human mesolimbic dopamine transmission with positron emission tomography. Part II: amphetamine-induced dopamine release in the functional subdivisions of the striatum. J Cereb Blood Flow Metab 23: 285-300. Medline

Morris ED, Yoder KK, Wang C, Normandin MD, Zheng QH, Mock B, Muzic RF Jr, Froehlich JC (2005) ntPET: a new application of PET imaging for characterizing the kinetics of endogenous neurotransmitter release. Mol Imaging 4:473-489. Medline

Morris ED, Kim SJ, Sullivan JM, Wang S, Normandin MD, Constantinescu CC, Cosgrove KP (2013) Creating dynamic images of short-lived dopamine fluctuations with lp-ntPET: dopamine movies of cigarette smoking. J Vis Exp 78. CrossRef Medline

Normandin MD, Schiffer WK, Morris ED (2012) A linear model for estimation of neurotransmitter response profiles from dynamic PET data. Neuroimage 59:2689-2699. CrossRef Medline

Perkins KA, Gerlach D, Vender J, Grobe J, Meeker J, Hutchison S (2001) Sex differences in the subjective and reinforcing effect of visual and olfactory cigarette smoke stimuli. Nicotine Tob Res 3:141-150. CrossRef Medline

Piper ME, Cook JW, Schlam TR, Jorenby DE, Smith SS, Bolt DM, Loh WY (2010) Gender, race, and education differences in abstinence rates among participants in two randomized smoking cessation trials. Nicotine Tob Res 12:647-657. CrossRef Medline

Porrino LJ, Lyons D, Smith HR, Daunais JB, Nader MA (2004) Cocaine self-administration produces a progressive involvement of limbic, association, and sensorimotor striatal domains. J Neurosci 24:3554-3562. CrossRef Medline

Scott DJ, Domino EF, Heitzeg MM, Koeppe RA, Ni L, Guthrie S, Zubieta JK (2007) Smoking modulation of mu-opioid and dopamine D2 receptormediated neurotransmission in humans. Neuropsychopharmacology 32 : 450-457. CrossRef Medline

Staley JK, Krishnan-Sarin S, Cosgrove KP, Krantzler E, Frohlich E, Perry E, Dubin JA, Estok K, Brenner E, Baldwin RM, Tamagnan GD, Seibyl JP, Jatlow P, Picciotto MR, London ED, O'Malley S, van Dyck CH (2006) Human tobacco smokers in early abstinence have higher levels of beta $2^{*}$ nicotinic acetylcholine receptors than nonsmokers. J Neurosci 26:87078714. CrossRef Medline

Sullivan JM, Kim SJ, Cosgrove KP, Morris ED (2013) Limitations of SRTM, Logan graphical method, and equilibrium analysis for measuring transient dopamine release with [(11)C]raclopride PET. Am J Nucl Med Mol Imaging 3:247-260. Medline

Weinberger AH, McKee SA (2012) Mood and smoking behavior: the role of expectancy accessibility and gender. Addict Behav 37:1349-1352. CrossRef Medline

Xu J, Azizian A, Monterosso J, Domier CP, Brody AL, Fong TW, London ED (2008) Gender effects on mood and cigarette craving during early abstinence and resumption of smoking. Nicotine Tob Res 10:1653-1661. CrossRef Medline

Yin HH, Knowlton BJ, Balleine BW (2006) Inactivation of dorsolateral striatum enhances sensitivity to changes in the action-outcome contingency in instrumental conditioning. Behav Brain Res 166:189-196. CrossRef Medline

Yoder KK, Wang C, Morris ED (2004) Change in binding potential as a quantitative index of neurotransmitter release is highly sensitive to relative timing and kinetics of the tracer and the endogenous ligand. J Nucl Med 45:903-911. Medline

Yoder KK, Constantinescu CC, Kareken DA, Normandin MD, Cheng TE, O'Connor SJ, Morris ED (2007) Heterogeneous effects of alcohol on dopamine release in the striatum: a PET study. Alcohol Clin Exp Res 31:965-973. CrossRef Medline 